\title{
Lugar del hecho dañoso: foro de competencia internacional por daño ambiental. Experiencia europea *
}

\author{
Harmful Event Location: International Jurisdiction \\ for Environmental Damage. European Experience
}

Pía M. Moscoso Restovic**

SUmario: I. Problemas del fuero "lugar del hecho dañoso"cuando concurren daños ambientales. II. Del hecho dañoso y sus fines. III. Concepto de hecho dañoso civil. IV. Diferencias entre el hecho dañoso civil y el hecho dañoso ambiental. V. Lo significativo del daño como discordia entre daños ambientales y daños civiles. VI. Dependencia del daño civil por la certidumbre del daño ambiental. VII. A modo de conclusión. VIII. Bibliografía.

* Artículo recibido el 15 de julio de 2011 y aprobado para publicación el 28 de septiembre de 2011.

El presente artículo ha sido desarrollado durante el periodo de Investigación en uso de Comisión de Estudios otorgada por la Universidad de Atacama. Fecha de conclusión del artículo: mayo de 2011.

** Abogada; magíster en Derecho de Minas, Aguas y Medio Ambiente, Universidad de Atacama Chile; doctora (c) en Derecho Internacional y Relaciones Internacionales, Universidad Complutense de Madrid España; profesora de Derecho Privado de la Universidad de Atacama.Contacto:pia.moscoso@uda.cl,piamoscoso@yahoo.com. 
RESUMEN: Este trabajo se dedica al análisis de la doctrina y la jurisprudencia del artículo 5.3 del Reglamento europeo (CE) 44/2001 Bruselas I. Específicamente, el análisis se refiere al concepto "hecho dañoso" en materias delictuales o cuasi-delictuales civiles por daño ambiental. Las reglas de competencia deben presentar un alto grado de previsibilidad. Sin embargo, el concepto "hecho dañoso" constituye un problema de interpretación cuando existe una relación entre daños civiles y daños ambientales. Por esta razón deben ser analizados: a) la importancia de los daños civiles, y b) la certeza de los daños ambientales. Estas cuestiones justifican otros criterios de vinculación con la jurisdicción competente.

Palabras clave: Derecho Internacional Privado, Reglamento Bruselas I, Competencia Judicial Internacional, principio favor laesi, daño ambiental internacional, responsabilidad por actos ilícitos, hecho dañoso.

ABSTRACT: This article analyzes doctrine and jurisprudence of Article 5.3 of the European Regulation (EC) 44/2001 Brussels I. Specifically, the analysis refers to the concept of "harmful event" on delict or quasi-delict (tort) civil for environmental damage. The rules of jurisdiction must be highly predictable. However, the concept "harmful event" may be a problem of interpretation when there is a relationship between environmental and civil damage. For this reason, it must be analyzed: a) the importance of civil damages, and b) the certainty of environmental damage. These issues justify different linking factor of international jurisdiction.

Descriptors: Private International Law, Brussels I Regulation, International Jurisdiction, favor laesi principle, international environmental damage, liability for wrongful acts, harmful event.

RÉSUMÉ: Ce travail se consacre à l'analyse de la doctrine et la jurisprudence de l'article 5.3 du Règlement européenne (CE) 44/2001 Bruxelles I. Spécifiquement, l'analyse porte sur le concept de "fait dommageable" en matières délictuelle ou quasi délictuelle civils pour dommage environnemental. Les règles de compétence doivent présenter un haut degré de prévisibilité. Toutefois, le concept de "fait dommageable" présente un problème de interprétation, quand il ya une relation entre dommages civils et dommages environnementaux. Pour cette raison, doivent être analysés: a) l'importance des dommages civiles, et b) la certitude des dommages environnementaux. Ces questions justifient un autre critère de rattachement avec la juridiction compétente.

Mots-Clés: Droit International Privé, Règlement Bruxelles I, Compétence internationale judiciaire, principe favor laesi, dommage international à l'environnement, responsabilité pour fait illicite, fait dommageable. 


\section{Problemas del FUero “LUGAR DEL heChO DAÑOSO” CUANDO CONCURREN DAÑOS AMBIENTALES}

Antes de comenzar este análisis, una advertencia, especialmente dirigida al juez que debe pronunciarse sobre su competencia internacional: existe un deber que recae sobre todo juez y que le obliga a no incurrir en el error de analizar su competencia judicial civil internacional (CJCI), conforme a los criterios que se aplican para el fondo del asunto. A contrario sensu, un juez no debe analizar el fondo del asunto aplicando criterios procesales propios de las normas de atribución de competencia. En efecto, lo que al principio parece obvio, debido a la diferente lógica que impera entre el derecho de fondo y el derecho procesal de atribución de la CJCI, en realidad no es tan clara porque existen vasos comunicantes que involucran riesgos.

El primer riesgo se produce en la tarea de determinar el tribunal competente, con prejuzgamiento del derecho de las partes, por la vía de haber definido a priori "los hechos" sobre los cuales se extiende la competencia.

Existe un segundo riesgo, y consiste en la eventualidad de perjudicar a una de las partes por la vía de clasificar algunos daños como directos y otros daños como indirectos para fines de CJCI; para luego continuar considerándolos así al aplicar el derecho de fondo.

Los criterios para clasificar los hechos deben obedecer a fines estrictamente procesales. Así, en este último caso, la determinación del tribunal competente debe tomar en consideración que buena parte de lo directo o indirecto de un daño guarda relación con el problema de resolver la vinculación entre dos hechos: el hecho generador y el hecho del resultado lesivo.

Conforme la necesidad de distinguir entre la dimensión procesal y la dimensión de fondo, aplicables al asunto internacional, se advierte la falta de escisión clara y absoluta entre las dimensiones procesal y de fondo. Prueba de esta aparente confusión se encuentra en el estatuto normativo comunitario aplicable al fondo de las obligaciones extracontractuales (Reglamento CE 864/2007 “Roma II”); el que trata conjuntamente los daños ambientales y los daños civiles asociados. Este esfuerzo del le- 
gislador comunitario evidencia la necesidad de unificar regímenes de responsabilidad extracontractual, que siendo diferentes por sus objetos obedecen a una misma finalidad: la reparación.

Tal idea de unificación es más útil en materia procesal que en materia del régimen de fondo aplicable al asunto. En efecto, la unificación de los procedimientos para determinar el tribunal competente de daños extracontractuales civiles y de daños ambientales puede resultar de mucha utilidad por los avances desarrollados previamente en el área civil. Lamentablemente también existe un riesgo en la unificación de los criterios que, sin duda, son distintos para materias ambientales que aquellos que inspiran las materias civiles. A mayor abundamiento, la función de las medidas cautelares, precautorias y de protección, tienen finalidades y procedimientos muy distintos en materia civil del que tienen en materia ambiental.

Por estas razones, la determinación del foro judicial por daño ambiental presenta notable complejidad en relación con la determinación foro judicial por daño civil; todo lo cual se ve agravado si existen elementos internacionales. Por tanto, las distinciones que la doctrina y la jurisprudencia europea han establecido para la determinación del lugar del hecho dañoso en materia civil no pueden aplicarse para la determinación del lugar del hecho dañoso en materia ambiental. Lamentablemente, la forma de abordar ambos daños ha sido conjunta, y el Tribunal de Justicia de las Comunidades Europeas de Luxemburgo (TJCE) ha permeado ambas dimensiones. Hoy, nos encontramos con que un pronunciamiento del TJCE sobre la CJCI de un tribunal para un caso de daños civiles asociados a una contaminación transfronteriza de 1976 (caso Bier/Minas de Potasio de Alsacia), también se aplica a los daños sufridos por consumidores o a los daños que afectan la imagen o el crédito de una persona. Por estas razones, y a efecto de no desvirtuar la pureza de los criterios para la determinación del tribunal competente, resulta que el análisis que se haga sobre el elemento daño en la relación extracontractual no debe considerar el modelo de responsabilidad civil aplicable. Así, y no obstante las multiplicidad de modelos de responsabilidad que pueden verse envueltos en un problema de responsabilidad internacional extracontractual, el elemento daño, común en todos ellos, es el principal punto de conexión con una jurisdicción, y es a él al cual nos referiremos en adelante. 
Por otra parte, el "hecho dañoso" (concepto que se diferencia de "daño", por referirse el primero tanto al lugar de origen como al lugar del resultado, y que deja al concepto "daño" como de sentido estricto), también puede analizarse como elemento de la obligación extracontractual internacional, para fines de determinar la CJCI. No obstante, se advierte que en la praxis, el trato que se ha dado al fuero "hecho dañoso" ha tendido a desvincularlo de los otros elementos de la relación extracontractual, aunque unos y otros incidan en la determinación del tribunal competente. Entre los otros elementos relacionados con el hecho dañoso sobresalen: a) el elemento personal (los sujetos involucrados), y b) la relación entre el hecho generador del daño y el resultado lesivo (usualmente denominado relación de causalidad entre la acción y el daño). Durante este trabajo ponemos énfasis en el último elemento de la relación extracontractual mencionado, esto es, la relación entre el hecho generador y el resultado lesivo. Tal relación que, desde el Derecho de fondo es abordada por la teoría de la causalidad, en nuestro caso en cambio, es analizada a objeto de determinar la extensión de los daños sobre los cuales se reclama la competencia de un tribunal.

En efecto, existe una vinculación entre el hecho generador y el resultado lesivo que incide directamente en la extensión del daño, y, por tanto, en la extensión de la CJCI. Habiéndose reconocido por la jurisprudencia del TJCE, en interpretación del artículo 5.3 del Reglamento 44/2001 Bruselas I, que existe un optio fori a favor de la víctima del daño, tal optio fori consiste en un derecho de recurrir a cualquiera de las dos jurisdicciones: a) la del lugar donde se originó el daño, y b) la del lugar donde se manifestaron sus consecuencias. En efecto, no olvidemos que el artículo 5.3 del Reglamento 44/2001 Bruselas I, habla de: "lugar donde se hubiere producido o pudiere producirse el hecho dañoso”.

Sin embargo, desde la perspectiva del juez llamado a pronunciarse sobre su CJCI, esta dualidad no se manifiesta como un derecho de opción, sino como un problema que consiste en determinar la extensión de su jurisdicción sobre los daños que se alegan. Por tanto, determinar cuáles son los "daños directos" es, precisamente, un problema de vinculación entre el "hecho generador" y el "resultado lesivo", y por tanto incide directamente en el contenido del concepto "hecho dañoso" al que se refiere el artículo 5.3 del Reglamento 44/2001 Bruselas I. 
En los casos de daños ambientales, encontramos la reproducción de la misma estructura básica descrita anteriormente para los daños civiles. En efecto, los elementos de la relación extracontractual, principalmente involucrados, serán: sujetos, daño y el vínculo que existe entre una acción generadora y un resultado lesivo. Por esta razón, tanto el hecho generador como el resultado lesivo hacen que convivan estrechamente daños civiles y daños ambientales. Tan estrecha es la relación entre daños civiles y daños ambientales que ninguno de ellos existe sin un hecho generador estrictamente ecológico. Por ejemplo, el vertido de riles, escoria o sustancias peligrosas a un río internacional es un hecho localizado originariamente en un Estado, que afecta potencialmente a dos o más Estados tanto desde la perspectiva ambiental (afectación de ecosistema), como desde la perspectiva civil (daño emergente y lucro cesante de cualquier actividad comercial de explotación del río, o incluso "daño moral ambiental").

Sin perjuicio de la estrecha relación entre ambas clases de daños, no existe una simetría entre los daños ambientales y los daños civiles. En efecto, existe una diferencia en cuanto al fin de la reparación y de la indemnización que persigue cada uno, y existe una diferencia en cuanto a los criterios que determinan la CJCI.

Si analizamos los daños civiles y los ambientales en sí mismos, como realidades separadas o desvinculadas entre sí, podríamos llegar a una multiplicidad de situaciones que darían como resultado - en los casos más extremos - la posibilidad de abrir foros de competencia especial en tantas jurisdicciones como lugares exhiben un daño (civil y/o ambiental). De aquí que podríamos preguntarnos si es conveniente condicionar los daños civiles a la ocurrencia de daños ambientales. Este debate no es nuestro objeto directo, sin embargo, durante el desarrollo de este trabajo se presenta un aspecto sustancial de dicho debate: la relación entre el hecho generador y el resultado lesivo determina la extensión de los daños que podrán ser conocidos por el tribunal competente. En efecto, el demandado puede resultar responsable sólo de algunos de estos daños civiles, según el derecho aplicable al fondo; sin embargo, el tribunal deberá considerar "todos los daños" (civiles y ambientales) para determinar la extensión de su competencia.

La importancia de esta aproximación se justifica en la incorporación que el Reglamento 864/2007 (Roma II), hace en su artículo 7o., de 
un derecho de opción que se aplica en similar régimen para los daños medioambientales como a los "daños sufridos por personas o bienes como consecuencia de dicho daño”. Si puede o no existir relación entre el artículo 7o. del Reglamento 864/2007 Roma II y el artículo 5.3 del Reglamento 44/2001 Bruselas I, es un debate que pasa por los criterios de interpretación del artículo 5.3 del Reglamento 44/2001 Bruselas I, aplicable para daños ambientales. Por ahora es un argumento más en nuestro objeto de interés: el análisis de las relaciones entre el lugar del hecho generador del daño y el lugar donde se manifestaron sus consecuencias. En otras palabras, un tribunal será competente si ha logrado resolver su vinculación con los hechos que se alegan, distinguiendo entre daños civiles y daños ambientales, no obstante el régimen de fondo que le corresponda aplicar.

Esta cuestión sólo ha sido abordada parcialmente por el TJCE, y guarda enorme complejidad en asuntos de contaminación internacional.

En este sentido, algunos autores ${ }^{1}$ vieron en el artículo 7o. del Reglamento 864/2007 Roma II supuestos que pueden relacionarse con la jurisprudencia del TJCE en torno al artículo 5.3 del Reglamento 44/2001 Bruselas I, en lo referente a los daños directos e indirectos. En estas opiniones, la Comisión que trabajó para el entonces futuro Reglamento 864/2007 Roma II habría acudido a criterios ya existentes para los puntos de conexión, los que se justificaban en relación con dos principios: a) responsabilidad objetiva y $b$ ) principio de prevención. ${ }^{2}$

Finalmente, y como señalábamos anteriormente, el elemento personal también guarda relativo interés con nuestro tema, en la medida

1 Fach Gómez, Katia, "La Prevención de catástrofes, la Unión Europea y el derecho internacional privado”, Jornada Técnica sobre Aspectos Jurídicos, Económicos y Sociales de las catástrofes, Foro Euromediterráneo para prevención de Desastres, disponible en http://www.proteccion civil.org/es/DGPCE/Informacion_y_documentacion/catalogo/carpeta04/cd1987-2003/doc/b5/ Juridica/3aCom_KatiaFach.pdf [revisado el 25 de abril de 2011]; Fach Gómez, Katia, op. cit.; Palao Moreno, Guillermo, "Hacia la unificación de las normas de conflicto en materia de obligaciones extracontractuales en Europa (una visión crítica del Anteproyecto de Propuesta de Reglamento Roma II)”, en varios autores, Derecho patrimonial europeo, España, 2003, p. 293.

El anteproyecto de propuesta de Reglamento del Consejo sobre la ley aplicable a las obligaciones extracontractuales señalaba: "the law applicable to a non-contractual obligation shall be the law of the country in which the damage arises or is likely to arise, irrespective of the country in which the event giving rise to the damage occurred and irrespective of the country or countries in which the indirect consequences of that event arise". 
que la extensión del daño clasifica también a las partes. En efecto, las partes, sean víctimas o demandados, serán civiles y ambientales, directas e indirectas, singulares o colectivas, etcétera. Sin embargo, el punto de conexión para todas ellas no está establecido en razón del elemento personal, sino en relación con el elemento objetivo de la relación jurídica internacional, esto es: el daño. En efecto, en las obligaciones extracontractuales internacionales, la aplicación del artículo 5.3 del Reglamento 44/2001 Bruselas I señala que el tribunal tiene CJCI especial, no en razón de la vinculación con los sujetos que intervienen en el foro, sino en exclusiva consideración al lugar donde se produce o pudiere producirse el hecho dañoso. De todo lo anterior resulta que el elemento personal se encuentra al servicio del lugar del hecho dañoso, en los delitos y cuasidelitos civiles. De aquí que la carga de la internacionalidad jurisdiccional será asignada al demandado, por ser considerado presunto responsable del daño, y con el objetivo de que una de las partes sea la que internalice los costes por su falta de cuidado, previsión o riesgo asumido.

Por otra parte, cuando el daño patrimonial se ha originado en un daño ambiental se abrirán tantos foros como lugares hayan verificado un daño. Sin embargo, esta aseveración, que ha sido objeto de limitaciones, también ha incidido en los sujetos de la relación extracontractual, de modo tal que existe la necesidad de que el demandante sea calificado como "víctima directa", y que demande la reparación e indemnización de "daños directos". Por tanto, a falta de un concepto autónomo de "parte directa", la extensión de los daños y su vinculación con el foro competente también calificará de directas o indirectas a las propias partes.

Comentario especial corresponde a la irrelevancia que presenta para el juez que está determinando su competencia, la circunstancia de que el modelo de responsabilidad que se sigue en el lugar del foro o el modelo de responsabilidad que corresponda según la ley aplicable sea subjetivo (o basado en la culpa del autor del daño), u objetivo (también denominado estricto o calificado por el riesgo). En ningún caso el juicio de la CJCI pasa por los sujetos, sino que pasa exclusivamente por el lugar donde se produce o pudiere producirse el hecho dañoso. Por esta razón, la subjetividad o grado de voluntariedad y participación en la acción, por parte del demandado, no juega ningún rol en la determinación del foro 
competente. No obstante, la acción debe ser analizada para determinar el grado de participación del demandado en el "hecho generador" del daño.

\section{DEL HECHO DAÑOSO Y SUS FINES}

El artículo 5.3 del Reglamento 44/2001, Bruselas I, supone dos dimensiones fundamentales para la comprensión del precepto: a) determinar qué se entiende por "materia delictual y cuasidelictual", y b) qué se entiende por "lugar donde se hubiere producido o pudiere producirse el hecho dañoso". Es la segunda dimensión la que abordaremos a continuación.

Previamente, algunas consideraciones. Al no existir, en el Reglamento 44/2001 Bruselas I, un concepto de obligación extracontractual, resulta que el énfasis que el intérprete debe poner en el artículo 5.3 del Reglamento 44/2001 Bruselas I se posiciona en la determinación de qué se entiende por "hecho dañoso"; como punto de conexión definitorio de la determinación de la CJCI de un tribunal. Por tanto, estarán al servicio del lugar del hecho dañoso todos los demás criterios, tales como: economía procesal, uniformidad en la aplicación del derecho comunitario e internacional, imputación de los riesgos e incluso la apertura de un foro de necesidad (este último, especialmente para los casos que involucren relaciones con países extracomunitarios).

Por otra parte, determinar el lugar del hecho dañoso reviste importancia porque fija los puntos de conexión tanto con el tribunal del lugar donde se originaron los daños como también con los tribunales donde se manifestaron las consecuencias lesivas. Así, en materia de daños ambientales, el lugar del hecho dañoso puede estar situado en más de un Estado a la vez y, con la acción del tiempo puede extender sus efectos a otros Estados no considerados inicialmente. Por su parte, el daño civil presenta características propias en cuanto a sus consecuencias y extensión sobre bienes futuros, oportunidades de negocio y lucro cesante. Cuando un juez es llamado a determinar su competencia sobre un hecho dañoso que reviste características civiles y ambientales deberá 
tomar en consideración que tal hecho dañoso es el conocido "hasta ese momento", y que nada obsta que la magnitud de las consecuencias posteriores motive a otras víctimas a presentar sus demandas ante otros foros, con igual o mejor derecho del que se arroja el primer tribunal que ha entrado a conocer del asunto. Así, el primer tribunal que conoce del asunto será normalmente aquel que se pronuncia sobre medidas cautelares y medidas de protección, y suele coincidir con el tribunal donde se originó la catástrofe ecológica. Sin embargo, esta circunstancia no quiere decir que por esta razón sea el único competente para conocer de todas las dimensiones del daño.

Asimismo, la naturaleza del hecho dañoso ambiental nos obliga a tener en consideración el fin preventivo que debe inspirar toda decisión judicial. En efecto, el juez no sólo es llamado a evitar la proliferación injusta de foros de competencia, que van en contra de los principios que el derecho internacional privado comunitario ha declarado, sino que también es necesario que el juez llamado a pronunciarse sobre su competencia cumpla un fin disuasivo de futuros hechos dañosos.

Este fin disuasivo ha sido anticipado por el análisis económico del derecho, señalando que en materia de responsabilidad extracontractual existe la necesidad de desplazar el interés jurídico (de fondo y procesal) desde un fin indemnizatorio a un fin social preventivo. ${ }^{3}$ Por esta razón, desde un punto de vista instrumental, las normas de la responsabilidad civil internacional, y con ellas las normas procesales accesorias, tienen también un carácter preventivo. Las normas de la responsabilidad extracontractual propenden (por la vía prescriptiva) que los costos del daño superen los

3 Tendencias sobre la ética de la responsabilidad social, desde la perspectiva del análisis económico del derecho en: Calabresi, Guido, El coste de los accidentes: análisis económico y jurídico de la responsabilidad civil, Barcelona, Ariel, 1970, p. 35; Posner, Richard, "El análisis económico del derecho en el Common Law, en el sistema romano-germánico, y en las naciones en desarrollo", Revista de Economía y Derecho, vol. 2, núm. 7, 2005; Barros Bourie, Enrique, "La responsabilidad civil como derecho privado: notas sugeridas por la reseña de C. Rosenkrantz al Tratado de Responsabilidad Extracontractual”, Estudios Públicos, núm. 112, 2008, pp. 309 338; Malloy, Robin Paul, Derecho y economía de mercado. Una nueva interpretación de los valores del derecho y la economía, trad. de Carmen Albaladejo, María Cristóbal, Esteban Flamini, Marcial Pons, 2007, pp. 138-150; Breyer, Stephen G., "Razonamiento económico y revisión judicial”, Estudios Públicos, núm. 109, 2008, pp. 37-55. 
costos de la prevención. ${ }^{4}$ Todo lo cual explica el derecho de opción que el legislador comunitario - y posteriormente el TJCE — entregaron al demandante de un daño ambiental plurilocalizado.

Asimismo, el juez deberá tener en consideración que las normas de responsabilidad civil internacional tienen un objetivo preventivo, y por tanto, correspondiéndole determinar su CJCI, también deberá hacer un balance sobre la eficacia de la prevención. ${ }^{5} \mathrm{Tal}$ es la importancia del fin preventivo de las normas de responsabilidad (de fondo y procesales). La doctrina ${ }^{6}$ ha señalado que en aquellos casos en los cuales el daño está repartido en incontables víctimas, que no tienen incentivo para demandar, entonces deberá ser el demandado quien asuma un costo mayor por cada denuncia, comparativamente al costo que le hubiera correspondido en caso de haber sido demandado por una víctima a la vez.

Así también justificamos la carga de la internacionalidad del proceso sobre el demandado de un daño ambiental transfronterizo o trasnacional.

Por otra parte, el fin preventivo de la responsabilidad extracontractual por daño ambiental consiste en una política comunitaria que cruza transversalmente la aplicación de la legislación ambiental en la Unión Europea, tanto a nivel legislativo-nacional, como a nivel de interpretación judicial. ${ }^{7}$ Es más, el hecho de que la Comisión europea haya previsto participar en el financiamiento de un programa de formación judicial en derecho ambiental, intercambiando información para la coordina-

4 Posner, Richard, El análisis económico del derecho, trad. de Eduardo Suárez, México, Fondo de Cultura Económica, 1998, p. 435.

5 Véase Pozo Pérez, Marta del, "Reflexiones sobre la Red judicial europea en materia civil y mercantil e Iber-Red”, La Ley, núm. 6717, del 21 de mayo de 2007, pp. 1-5, y Cienfuegos Mateo, Manuel, Efectos Jurídicos de las sentencias prejudiciales interpretativas del TJCE y su aplicación judicial en los Estados miembros, Tesis para obtener el título de doctor en derecho, Barcelona, Universidad Pompeau Fabra, 1995.

6 Barros Bourie, Enrique, op. cit., pp. 216-219, y pp. 242-243; Cadiet, Loï, Les métamorphoses du prejudice, en les métamorphoses de la responsabilité, París, Sixiéme Journées René Savatier, Presses Universitaires1997, p. 42.

7 Véase Comunicación de la Comisión al Parlamento europeo, al Consejo, al Comité Económico y Social europeo y al Comité de las regiones, sobre la aplicación de la legislación ambiental comunitaria Bruselas 18 de noviembre de 2008 COM (2008) 773 final. Disponible en http: / / www.europarl.europa.eu/meetdocs/2004_2009/documents/dv/com_com(2008)0773_/ com_com(2008)0773_es.pdf [revisado el 19 de marzo de 2011]. 
ción y cooperación de redes judiciales ${ }^{8}$ demuestra la importancia del rol judicial preventivo a nivel nacional. El fundamento se encuentra en el artículo 226 del Tratado CE, y en la utilización por los jueces nacionales del artículo 234 de dicho Tratado.

Por esta razón, el foro especial señalado en el artículo 5.3 del Reglamento Bruselas I, no sólo establece un vínculo objetivo entre el hecho dañoso y el tribunal del lugar donde se produce o pudiere producirse el hecho dañoso. El artículo 5.3 también entrega subliminalmente la carga de la internacionalidad al demandado del daño extracontractual, en tantos lugares como consecuencias directas se hayan manifestado.

Las limitaciones a la multiplicidad de foros que se pueden abrir por esta vía es el principal objeto de este capítulo, desde la perspectiva del vínculo que existe entre el hecho generador del daño y el resultado lesivo. En efecto, existe la necesidad de aclarar cuál es el título de competencia que tiene el demandante para acudir a un tribunal determinado en caso de daños ambientales plurilocalizados, de distinta naturaleza y en permanente desarrollo.

Finalmente, el objetivo reparatorio e indemnizador de la responsabilidad extracontractual coexiste con un objetivo punitivo estrechamente vinculado a la prevención. ${ }^{9}$ Si bien, será el derecho aplicable al fondo del asunto el que se ocupe de esta materia, conviene considerar que, para el demandante, la elección del tribunal competente tendrá en especial consideración la integridad en la indemnización y las garantías de no repetición que le ofrezca una jurisdicción determinada. Para dar eficacia a la política comunitaria de responsabilidad extracontractual por daño ambiental internacional deberá entenderse que las normas del Reglamento 44/2001 Bruselas I sobre responsabilidad delictual y cuasidelictual son disuasivas.

8 Tal es el caso del Foro Europeo de Jueces para el Medio Ambiente y la Asociación de Jueces Europeos de Derecho Administrativo.

9 Es lo que se ha denominado “daños punitivos”. Véase Cane, Peter, The Anatomy of Tort Law, Oxford, Hart Publishing, 1997, p. 102; García Matamoros, Laura y Herrera Lozano, María, "El concepto de los daños punitivos o punitive damages", Revista Estudios Socio-Jurídicos, Bogotá, Universidad del Rosario, año 5, núm. 1, pp. 211-229; Ruiz García, Juan, “Otra vuelta de tuerca a los daños punitivos”, Revista para el Análisis del Derecho, disponible en http: / / www. indret.com/pdf/438_es.pdf(revisado el 7 de marzo 2011). 
En la nomenclatura del Reglamento 44/2001 Bruselas I, el hecho dañoso no equivale a daño. Considerando lo señalado por algunos autores, ${ }^{10}$ sobre la ambigüedad "deliberada" con la que fue redactada el precepto, estimamos que el problema por la falta de localización del forum loci delicti comissi pasa necesariamente por la naturaleza territorial del foro para daños civiles y la naturaleza geográficamente dispersa del daño ambiental.

Considerando, asimismo, que el Reglamento 44/2001 Bruselas I se aplica a materias civiles y mercantiles, se ha entendido que el hecho dañoso se extiende al "daño patrimonial de quien alega un perjuicio". ${ }^{11} \mathrm{No}$ existe un concepto de hecho dañoso ambiental, sino sólo una aproximación a la noción de hecho dañoso, exclusivamente civil.

Por otro lado, como no existe una definición de obligación extracontractual, tampoco podemos encontrar por esta vía una definición de sus elementos, y entre ellos el que nos interesa: el daño. Tanto el Reglamento Bruselas I como el Reglamento Roma II reconocen que el concepto de obligación extracontractual varía en cada Estado, y por tanto varían también el sentido y alcance de los elementos de la obligación extracontractual. Este problema se ha decantado por la vía de los conceptos autónomos. ${ }^{12}$

Sin embargo, la creación de conceptos autónomos supone que el TJCE identifique los mínimos comunes a todos los sistemas jurídicos y que establezca la limitación del concepto en razón de los fines del derecho comunitario de: certeza y previsibilidad del sistema. ${ }^{13}$ En este

10 Comentando la indecisión deseada de los autores del Reglamento 44/2001: Palao Moreno, Guillermo, op. cit. p. 57, citando el Informe de P. Jenard, “Informe sobre el Convenio relativo a la competencia judicial y a la ejecución de resoluciones judiciales en materia civil y mercantil”, D.O.C.E., núm. C189/122 del 18 de julio de 1990, p. 145.

11 Conclusiones del abogado general señor L. A. Geelhoed, presentadas el 31 de enero de 2002, Asunto C-334/00, Fonderie Officine Meccaniche Tacconi Spa. Apartado 16.

12 Reglamento CE 864/2007, Roma II. Considerando 11.

13 De la precisión del hecho dañoso y debates en otros temas véase Miguel Asensio, Pedro de, "Competencia Judicial en materia de indicaciones geográficas y denominaciones de origen”, en Ubertazzi y Muniz Espada (coords.), Le Indicazoni di Qualitá degli alimenti, Diritto 
sentido, el TJCE señaló en la sentencia Marinari ${ }^{14}$ que no fue intención del Convenio de Bruselas de 1968 vincular las normas de competencia territorial del artículo 5.3 a las disposiciones nacionales sobre responsabilidad civil extracontractual. Por tanto, interpretar el Convenio de Bruselas de 1968, según el derecho aplicable al fondo del asunto, hace depender la determinación de la competencia a "circunstancias inciertas" propias de las especificidades de cada sistema nacional. Resultando así incompatible con el principal objetivo del Convenio, que consiste en establecer reglas de competencias ciertas y previsibles.

Cuando el tribunal llamado a pronunciarse sobre su CJCI se enfrenta al concepto de daño civil debe sortear un doble desafío: distinguir entre daño ambiental y daño civil, máxime si ambas clases de daños derivan del mismo hecho generador al que se refiere el artículo 5.3 de Bruselas I.

Existen definiciones de daño ambiental ${ }^{15}$ que son de tal amplitud que resultan poco funcionales para la determinación de la CJCI, y arrojan más dudas aún sobre la extensión de los hechos dañosos civiles asociados. En efecto, el medio ambiente abarca elementos naturales, pero también abarca elementos socioculturales y las permanentes interacciones entre todos los anteriores.

Cosa distinta ocurre con el daño patrimonial strictu sensu, conforme al cual el objeto de la indemnización, satisface plenamente el objeto del derecho subjetivo. Teniendo definido el derecho subjetivo podemos

Internazionale ed europeo, Milán, Giuffrè Editore, 2009, pp.13-18; Miguel Asensio, Pedro Alberto de, "La protección transfronteriza de los bienes inmateriales en el comercio internacional”, Cursos de derecho internacional y relaciones internacionales deVitoria-Gasteiz 2008, Bilbao, Universidad del País Vasco, 2008, pp. 365-446; Gómez Ligüerre, Carlos Ignacio, "Problemas de jurisdicción competente y de derecho aplicable en pleitos de responsabilidad civil extracontractual”, Indret: Revista para el Análisis del Derecho, Barcelona, núm. 2, 2009.

14 STJCE C-364/93, Rec. p. I-2719, asunto Marinari. Apartado 18. Véanse también Conclusiones del Abogado General señor L.A. Geelhoed, presentadas el 31 de enero de 2002, en el asunto C-334/00, Fonderie Officine Meccaniche Tacconi Spa. Apartado 42.

15 Reglamento CE 864/2007 Roma II. Considerando 24: Por “daño medioambiental” debe entenderse el cambio adverso de un recurso natural, como el agua, el suelo o el aire, el perjuicio a una función que desempeña ese recurso natural en beneficio de otro recurso natural o del público, o un perjuicio a la variabilidad entre los organismos vivos. Concepto que debe complementarse con la Directiva 2004/35/CE del 21 de abril de 2004, sobre responsabilidad medioambiental en relación con la prevención y reparación de daños medioambientales, artículo 2 y considerandos 4, 5 y 8 , principalmente. 
conocer cuál es el bien jurídico conculcado: propiedad. Todo lo cual constituye un beneficio en la limitación del daño.

Sin embargo, cuando nos referimos a daños ambientales y a daños civiles que son concurrentes del mismo hecho generador; la amplitud del daño ambiental "contamina", la noción de daño civil extracontractual, y por tanto, lo hace partícipe de los debates sobre la amplitud del concepto de daño ambiental. El problema que surge entonces es: para determinar el hecho dañoso civil ¿debemos asociarlo necesariamente a un daño ambiental?

Al respecto, las codificaciones civiles ${ }^{16}$ advierten dos tendencias en la delimitación del concepto de daño civil.

Por un lado, existen sistemas jurídicos (coincidentes con sistemas herederos de tradición francesa) donde el daño civil extracontractual está asociado a un "derecho subjetivo". ${ }^{17}$ En estos sistemas la antijuridicidad del daño es la que da lugar a la responsabilidad extracontractual. Por tanto, el juicio de reproche civil supone asociar necesariamente el daño civil a un daño ambiental. Esta perspectiva es muy útil si queremos permear al daño civil de la lógica del daño ambiental, v. gr. de un principio favor laesi en beneficio del demandante civil.

16 Barros Bourie, Enrique, op. cit., p. 220.

17 Dos ejemplos en: a) STS 3591/1998, Sentencia del Tribunal Supremo español de 14 de marzo de 2005. Procedimiento: casación, declara que: "la protección del medio ambiente y la responsabilidad en que incurre quien lo menoscaba como bien de la colectividad difícilmente puede ser objeto de consideración en el ámbito del Derecho civil. Sólo un aspecto de la protección del medio ambiente, el que se refiere a la protección específica de derechos subjetivos patrimoniales, ha sido objeto de una reiterada jurisprudencia civil, que contempla, sustancialmente, inmisiones en fincas o propiedades vecinas”, y b) STS 882/98, sentencia del Tribunal Supremo español de 28 de enero de 2004. Procedimiento: casación, interpreta el artículo 1908 del Código Civil conforme con el artículo 45.1 de la Constitución, señalando que exceden la formulación del precepto "las inmisiones intolerables y al medio ambiente". Asimismo, consideró que no era misión del derecho civil proteger el medio ambiente, sino bajo la "protección específica a derechos subjetivos patrimoniales" por agresiones ambientales. Asimismo, declaró que "el cumplimiento de normativa reglamentaria no impide la apreciación de responsabilidad cuando concurre la realidad del daño causado por la persona física o jurídica", como lo fueron daños a propietarios de fincas y de cabezas de ganado por una intensa por contaminación a base de fluorosis. 
En otros sistemas, en cambio (coincidentes con los sistemas del common law) la noción de daño no está asociada a un bien jurídico. ${ }^{18}$ En estos sistemas se obedece principalmente a la realidad fenomenológica. En tales casos la noción de daño civil adquiere notable amplitud porque mira más a los "intereses" patrimoniales y extrapatrimoniales en juego que a los fines de justicia ambiental que se encuentran detrás. Esta última tendencia ha sido objeto de numerosas críticas atendida la elefantiasis que ha sufrido la responsabilidad civil extracontractual.

Como se observa, la relación daño ambiental y daño civil adolece de problemas de delimitación que, como se verá más adelante, inciden en la determinación del tribunal competente.

Considerando que la tendencia del derecho civil contemporáneo es la expansión de los intereses que se protegen a través de las acciones civiles de responsabilidad extracontractual, ${ }^{19}$ existe una fuerte necesidad por establecer los límites del concepto daño civil para efectos de determinar el tribunal competente. Al respecto, la imputación objetiva del daño, ${ }^{20}$ esto es, la asociación a los fines de justicia preventiva, distributiva y retributiva establecidos para el sistema de responsabilidad extracontractual comunitario, nos ayudan a limitar el concepto por medio de la justificación normativa a un interés jurídico.

En efecto, ocurrido un daño ambiental, existen múltiples intereses involucrados, entre ellos, intereses públicos de seguridad y protección de los recursos naturales e intereses privados derivados del aprovechamiento de los recursos naturales. Desde la perspectiva de las partes involucradas, el interés o derecho vulnerado entrega luces sobre la vinculación entre hecho generador y resultado lesivo. Por tanto, toda aproximación a una limitación del concepto daño civil (para efectos de determinar el tribunal competente) va más allá que el análisis en solitario del concepto de hecho dañoso.

18 Mención especial, para los sistemas que no siendo del Common Law, restringen los bienes jurídicos a aquéllos tipificados por el legislador en un catálogo: BGB, artículo 823.

19 Situación que se presenta especialmente en los sistemas de tradición francesa. Véase Carbonnier, Jean, Droit Civil Les Obligations, 22a. ed., Presses Universitaires de France, París, 2000, t. IV, p. 385; Cadiet, Löic, La méthamorphoses du préjudice, en Les méthamorphoses de la responsabilité, París, Sixièmes Journées René Savatier, Presses Universitaires de France,1997 p. 39.

\footnotetext{
20 También denominada imputación normativa por basarse en el espíritu de la norma.
} 
Por su parte, la relación entre el hecho generador y el resultado va más allá de la mera relación de causalidad natural que pueda existir entre ellos. Para el tribunal resulta de especial interés limitar la extensión del daño civil respecto de la extensión del daño ambiental, todo lo cual podría ocurrir si el tribunal tuviera en consideración algunos elementos de juicio y de imputación normativa sobre la relación entre el hecho generador y el resultado. Por ejemplo, y conforme señalábamos anteriormente, la noción de daño civil puede asociarse a un interés concreto que detenga la expansión de la responsabilidad civil y no afecte la amplitud de daño ambiental.

\section{DifERENCIAS ENTRE EL HECHO DAÑOSO CIVIL Y EL HECHO DAÑOSO AMBIENTAL}

Sin perjuicio de los fundamentos que el principio favor laesi le otorga al demandante civil de daños directos, para presentar su demanda en el lugar donde se producen estos daños, y especialmente en el lugar de su propio domicilio, es lógico preguntarnos si cualquier daño civil — por el solo hecho de estar asociado a un daño ecológico - puede abrir un foro especial de competencia.

Creemos que no, que tal característica recae sólo en el hecho dañoso civil directo. ${ }^{21}$ Prueba de ello radica en las notables diferencias de extensión que arrojan ambas clases de daño.

\section{LO SIGNIFICATIVO DEL DAÑO COMO DISCORDIA ENTRE DAÑOS AMBIENTALES Y DAÑOS CIVILES}

Por regla general, los problemas de daño civil significativo están relacionados con la determinación del valor de la cosa que se solicita reparar

21 Sobre la extensión del concepto daño véase razonamiento en Conclusiones del Abogado General señor F. G. Jacobs presentadas el 18 de septiembre de 2003, Asunto C-18/02, Danmarks Rederiforening, en nombre de DFDS Torline A/S. Apartados 38-40. 
o con el monto de la indemnización. En este sentido, un tribunal se verá obligado a justificar muy bien la declinación de su competencia si cientos de personas se ven perjudicadas extracontractualmente, por un hecho ocurrido en otro Estado, pero cuyos efectos se sienten en la jurisdicción del primero v. gr. pérdida de una importante cuota de mercado, imposibilidad de cumplimiento de gran cantidad de obligaciones contractuales, etcétera, motivadas todas por la ocurrencia de una catástrofe ambiental ocurrida en otro Estado.

En materia de daños ambientales lo significativo se eleva a "condición” para el nacimiento de la obligación extracontractual ${ }^{22}$ ¿debe exigirse la misma "condición" para abrir un nuevo foro civil?

El artículo 2o. de la Directiva 2004/35/CE del 21 de abril de 2004 sobre responsabilidad medioambiental en relación con la prevención y reparación de daños medioambientales ha definido daño medioambiental como: “a) los daños a las especies y hábitats naturales protegidos, es decir, cualquier daño que produzca efectos adversos significativos en la posibilidad de alcanzar o de mantener el estado favorable de conservación de dichos hábitats o especies". Asimismo, ha señalado que "el carácter significativo" de dichos efectos se evaluará en relación con el estado básico, y conforme los criterios del Anexo I. ${ }^{23}$

Por tanto, siendo una condición para el nacimiento de la obligación extracontractual que el daño ambiental sea significativo; entonces el juez podría declararse incompetente sobre un delito o cuasidelito que no existe. Sin perjuicio de lo anterior, podría llegar a la misma conclusión defiriendo el problema hasta la sentencia definitiva que se pronuncia sobre el fondo del asunto. En este último caso, los daños no significa-

22 Barros Bourie, Enrique, op. cit., p. 227.

23 Directiva 2004/35/CE de 21 de abril de 2004 sobre responsabilidad medioambiental en relación con la prevención y reparación de daños medioambientales, idea que se reproduce en: artículo 2.1 incisos b) y c), 2.15, y Anexo 1 . En el mismo sentido, encontramos que el daño debe ser significativo en: Directiva 92/43/CEE del Consejo, del 21 de mayo de 1992, relativa a la conservación de los hábitats naturales y de la fauna y flora silvestres, artículo 12. Convenio de Berna relativo a la conservación de la vida silvestre y del medio natural de Europa (Decisión 82/72/CEE del Consejo, de 3 de diciembre de 1981), artículo 6. Directiva 79/409/CEE del Consejo, del 2 de abril de 1979, relativa a la conservación de las aves silvestres, artículo 5 . 
tivos podrían ser conocidos en forma acumulada con los daños mayores y significativos, por razones de pertinencia y economía procesal.

Por otro lado, un mismo hecho dañoso puede representar distinta valoración significativa en materia civil y en materia ambiental. En materia ambiental, el TJCE ha señalado que el artículo 5 de la Directiva 2004/35, sobre responsabilidad medioambiental en relación con la prevención y reparación de daños medioambientales, busca "evitar daños previsibles a especies protegidas cuando produzcan efectos adversos significativos en la posibilidad de alcanzar o de mantener el estado favorable de conservación de dichas especies". ${ }^{24}$

Esta misma doctrina jurisprudencial ha señalado que lo "significativo" dependerá de las circunstancias, y así tenemos que en algunos casos será "significativa" la afectación a un gran número de ejemplares de una especie (por aplicación de la Directiva 2004/35/CE sobre responsabilidad medioambiental en relación con la prevención y reparación de daños medioambientales), mientras que en otros casos, serán significativos efectos menos intensos si afectan a ejemplares singulares (por aplicación de la Directiva 92/43/CEE relativa a la conservación de los hábitats naturales y de la fauna y flora silvestres).

A propósito del daño significativo conviene preguntarse también cuáles son las molestias que la doctrina de la responsabilidad civil extracontractual ha calificado como de "excesivas", por lo "anormal" del daño, y cuáles daños son menos relevantes, normales o que obedecen al tráfico normal de relaciones internacionales. ${ }^{25}$

Como vemos, la significación del daño no es baladí, y dependerá si hablamos de daños civiles o de daños ambientales, pudiendo variar, incluso, la atribución de competencia.

24 STJCE del 18 de mayo de 2006, Asunto C-221/04, Comisión contra Reino de España.

25 Von Bar, Christian, Gemeineuropä̈sches Deliktsrecht, Múnich, Beck, 1996, t. II, p. 5; citado por Barros Bourie, Enrique, op. cit., p. 227; Diez-Picazo, Luis, Derecho de daños, Madrid, Civitas, 1999, p. 307; Viney, Geneviève y Jourdain, Patrice, "Les conditions de la responsabilité", en Jacques Ghestin, Traité de Droit Civil, 2a. ed., París, Librairie Générale de Droit et de Jurisprudence, 1998, p. 1063; Le Tourneu, Phillippe y Cadiet, Löic, Droit de la Responsabilité et des Contrats, París, Dalloz Action, 2002, p. 1295; Domínguez Águila, Ramón, "Consideraciones en torno a la noción en la responsabilidad. Una visión comparatista”, Revista de Derecho de la Universidad de Concepción, 1990, p. 128. 
Por ejemplo, las relaciones de vecindad entre los Estados imponen servidumbres que, dependiendo del lugar y condiciones, pueden afectar un determinado ecosistema del Estado sirviente; las actividades en un Estado pueden afectar la migraciones de ciertas especies en Estados vecinos; la calidad de los ríos internacionales puede verse alterada por actividades en un lado de la frontera; los mismos ríos internacionales pueden verse objeto de crecidas o disminuciones que obedezcan en parte a la intervención humana y en parte a fenómenos naturales periódicos; la desertificación de algunas zonas limítrofes de un país puede deberse al mal manejo del recurso hídrico o agotamiento de napas subterráneas en el país vecino, etcétera. En los casos anteriores, algunos de los problemas expuestos pueden no tener suficiente significación para constituir un daño civil en el momento en el que se requiere la intervención judicial. Todo lo cual no deja de ser un daño civil asociado, por la "disminución progresiva en el tiempo" de actividades económicamente dependientes directas del recurso natural en proceso de agotamiento.

Si bien muchas de estas circunstancias se analizan durante el curso del juicio y se ponderan según el derecho aplicable al fondo del asunto, existen problemas que se asocian a las medidas cautelares, preventivas o de protección, que también se analizan en sede prejudicial. No ahondaremos sobre este tema sino para ilustrar que el daño ambiental, por naturaleza acumulativo, tendrá mayor gravedad según la evidencia del paso del tiempo. Por tanto, la gravedad del daño ambiental tendrá una ponderación cronológicamente distinta al daño civil. Muchos de los efectos civiles del hecho dañoso se caracterizan por ser inmediatos, y a diferencia de los daños ambientales que se explicitan y manifiestan más claramente con el tiempo, los daños civiles sufren el efecto contrario. El tiempo conspira contra la prueba del daño civil y puede desvirtuar su gravedad. ${ }^{26}$

26 Un ejemplo del reconocimiento evolutivo de las ciencias ambientales y de la función preventiva de la responsabilidad civil “infrautilizada” en: STS 3625/2007. Sentencia del Tribunal Supremo español, núm. de recurso: 2300/2000, núm. de resolución: 589/2007. Procedimiento: casación. Ha señalado: "Especialistas de la doctrina científica han destacado cómo ya las sentencias del Tribunal Supremo de 9 de abril de 1866 y 12 de mayo de 1891 rechazaron, en el ámbito del Derecho civil, el principio o teoría de la denominada «pre-ocupación», en virtud de la cual se negaba la indemnización por actividad contaminante a quien se estableciera en el lugar después de haberse iniciado tal actividad. Aunque en el siglo XIX no se hubiera 
Por las razones señaladas anteriormente, el juez llamado a pronunciarse sobre su competencia, por ejemplo, para medidas cautelares o de protección, deberá considerar la gravedad potencial del hecho dañoso civil. Como vimos, la gravedad del daño ambiental difiere de la gravedad del daño civil, por tanto, proponemos que la gravedad o significancia del hecho dañoso civil esté ligada a la afectación de un bien, de un interés o de un derecho, más que analizar aspectos cuantitativos relacionados con la ocurrencia del daño ecológico.

\title{
VI. DEPENDENCIA DEL DAÑO CIVIL POR LA CERTIDUMBRE
}

\author{
DEL DAÑO AMBIENTAL
}

La jurisprudencia del $\mathrm{TJCE}^{27}$ y el Reglamento Bruselas ${ }^{28}$ se refieren a la “carga de la internacionalidad jurisdiccional”, íntimamente ligada con el juicio de "previsibilidad" que debió tener el demandado, tanto en la comisión del daño como en su localización. Este tema se aborda desde la perspectiva de la previsibilidad del título de jurisdicción en lo relativo al vínculo de conexión.

acuñado todavía ese término, lo cierto es que la sentencia de 1866 rechazó la aplicabilidad al caso de la Ley 22, título 8, partida 5, a favor de una compañía minera demandada por humos y vertidos perjudiciales para la finca y ganado del vecino, razonando que la adquisición de la dehesa por el perjudicado después de haberse iniciado parte de la actividad minera no suponía consentimiento de los perjuicios ni renuncia a reclamar por ellos, y la sentencia de 1891 negó que constituyera enriquecimiento injusto la pretensión indemnizatoria de quien había construido cerca de una escombrera perteneciente a una compañía de ferrocarriles, la cual acabó derrumbándose y causando daños a la construcción del demandante. Y como quiera que en el siglo XX fueron frecuentes los pronunciamientos del orden jurisdiccional civil que satisfacían las pretensiones de quienes se consideraban perjudicados por actividades contaminantes, existe hoy una importante corriente en la doctrina científica que propugna una potenciación de la vía civil como especialmente idónea para la tutela de los intereses medioambientales, a partir de la idea de que hasta ahora está infrautilizada sobre todo en la vertiente preventiva" (énfasis añadido).

27 STJCE 33/78 asunto Somafer vs. Saar-Feerngas, STJCE C-26/91 asunto Jakob Handte vs. Mecano Chimoques, STJCE C-440/97 asunto IE Groupe Concorde y otros vs. Capitaine commandant le navire "Suhadiwarno Pnajan" y otros, STJCE C-96/00 asunto Gabriel, TJCE C-256/00 asunto Besix, STJCE C-334/00 asunto Fonderie Officine Meccaniche Tacconi.

28 Considerando 11o. del Reglamento 44/2001 Bruselas I. 
Para evitar caer en equívocos, abordamos la "certidumbre" como un concepto distinto al de previsibilidad, esto es, no desde el vínculo sino desde el conocimiento y disposición que el demandado ha demostrado tener asumiendo un eventual daño ambiental y las consecuencias civiles del mismo.

En materia de daños ambientales, la certidumbre del daño está asociada al conocimiento científico disponible, y al grado de anticipación del resultado que es exigible del demandado. ${ }^{29}$ Este tema ha sido tratado por la teoría de la responsabilidad de fondo. ${ }^{30}$

Desde la perspectiva de la CJCI, el lugar donde "pudiere producirse el hecho dañoso civil" no es un problema de negligencia, sino un problema de relación directa con el hecho generador del daño ecológico. En efecto, el daño ecológico puede verificarse a distancia del lugar de origen o manifestar sus consecuencias mucho tiempo después de haber ocurrido el hecho principal. Todo lo cual influirá necesariamente en el hecho dañoso civil.

Por otra parte, todo daño civil que se busque indemnizar debe ser cierto, esto es, deber ser real actualmente o en el futuro. ${ }^{31}$

El problema con la certidumbre del daño afecta en mayor medida al daño ambiental que al daño civil. De aquí que encadenar ambas clases de daños puede presentar algunos inconvenientes. Mientras la certidumbre del daño civil guarda relación con la idea de actualidad al momento de la presentación de la demanda (y con el lucro cesante); en el daño ambiental, en cambio, la certidumbre del daño presente depende

29 Véase STS 5541/2008, núm. de recurso: 942/2003 Madrid, 29 de octubre de 2008, citando la STS del 19 de mayo de 2003, la cual se pronunció sobre una demanda de perjuicios por daño ambiental en razón de un vertedero ilegal en una propiedad comprada, declarándose a favor de acciones de responsabilidad extracontractual, en lugar de acciones de saneamiento derivadas de la compraventa propuestas por el demandado. "Esta Sala ha declarado que sería enormemente injusta la aplicación del artículo 1484 (sobre saneamiento de vicios redhibitorios) a unos vicios que está probado que se ponen de relieve con el tiempo, no dentro del reducido plazo de seis meses que concede el Código Civil para la acción de saneamiento”.

30 Como uno de los elementos de la obligación extracontractual: la negligencia.

31 Mazeaud, Henri et al., Leçons de droit civil. Obligation Théorie Générale, 9a. ed., París, Montchrestien, 1998, t. II, p. 416; Carbonier, Jean, Droit Civil. Les Obligations, París, Presses Universitaires de France, 2000, t. IV, p. 378; Viney, Geneviève y Jourdain, Patrice, op. cit., p. 66; Barros Bourie, Enrique, op. cit., pp. 236-240. 
de la prueba (la certidumbre del daño ambiental futuro es esencialmente probabilística). Por otro lado, no existen presunciones de daño ambiental.

El daño ambiental se clarifica e intensifica con el tiempo. Por tanto, determinar el daño futuro supone tener la capacidad de asegurar razonablemente su ocurrencia. Tal es el caso de las enfermedades cancerígenas causadas por agentes contaminantes, que se manifiestan en unas personas sí y en otras no, o incluso pueden saltar una generación. En estos casos la víctima no puede esperar a que se materialice el daño para demandar su indemnización, pues normalmente los problemas de la prueba se intensifican con el paso del tiempo.

Algunos autores, refiriéndose al daño futuro, han recurrido a la vieja fórmula de la jurisprudencia francesa que señala que el daño futuro es la "prolongación directa y probable de un estado actual de cosas y es susceptible de una evaluación inmediata”. ${ }^{32}$

Para el caso de los daños ambientales, dicha prolongación supone un cálculo probabilístico razonable y fundado en antecedentes científicos, que aconseje por economía procesal, evitando una sucesión de juicios que se desencadenen en el tiempo, derivados del mismo hecho dañoso.

Son ajenos a este juicio: la participación de la víctima, la pérdida de oportunidad para evitar el daño y, en general, cualquier circunstancia que atienda a la culpabilidad de las partes en la ocurrencia del hecho. En este sentido, el hecho dañoso pudo haberse ocasionado no sólo por la ocurrencia del hecho generador, sino que pudo haberse visto agravado por la intervención posterior de alguna de las partes. Este problema, sólo será de interés en la determinación de la competencia judicial, cuando se planteen conexiones entre el hecho generador y el resultado dañoso, que sean de difícil prueba por haber intervenido varias causas en la producción del resultado dañoso final.

La certidumbre del daño civil también ha sido objeto de controversia ante el TJCE, cuando puestos ante la ilicitud de una conducta, el concepto de hecho dañoso ha sido usado para materia contractual y materia

32 Barros Bourie, Enrique, op. cit., pp. 236-240, Alessandri Bessa, Arturo, De la responsabiliad extracontractual en el derecho civil chileno, Santiago, Imprenta Universitaria, 1943, p. 214; Domínguez Águila, Ramón, “Consideraciones en torno a la noción en la responsabilidad. Una visión comparatista”, Revista de Derecho de la Universidad de Concepción, 1990, p. 148. 
extracontractual a la vez. En esta oportunidad, el TJCE señaló que los daños que se estiman extracontractuales deben ser ciertos, de tal forma que si la demandante no ha soportado un "daño específico", no hay lugar para una demanda subsidiaria de responsabilidad a título extracontractual, entendiéndose que todos los perjuicios son contractuales. ${ }^{33}$

En conclusión, la certidumbre del daño es un criterio limitativo de la extensión del daño, y por tanto entrega contenido al concepto hecho dañoso. Considerando que el TJCE ha tratado de precisar la extensión del fuero hecho dañoso civil, tenemos que a mayor certeza sobre la magnitud del daño ecológico, mayor certeza sobre los lugares a los que se extiende el daño civil.

\section{A MODO DE CONCLUSIÓN}

El concepto "hecho dañoso" del Reglamento 44/2001 Bruselas I experimenta una evolución jurisprudencial que puso, desde 1976, el énfasis en la determinación de dos hechos: a) el hecho generador y b) el hecho del resultado dañoso (o daño en sentido estricto). Desde entonces y hasta la fecha, el TJCE ha establecido las limitaciones a este concepto con el objeto de evitar el aumento de foros de competencia.

Sin embargo, cuando el hecho dañoso al que nos referimos, no es exclusivamente civil, esto es, cuando además se relaciona con un "hecho dañoso ambiental”, entonces tenemos que los criterios clásicos de interpretación no son suficientes para determinar quién tiene la carga de la litigación internacional.

Por esta razón hemos propuesto que la CJCI por daños civiles asociados a daños ambientales debe considerar tanto la gravedad potencial del daño civil como la certidumbre del daño ambiental. Uno y otro están íntimamente ligados en la determinación de la extensión de la competencia, y por tanto en la carga de la litigación internacional que afectará a una de las partes.

33 Conclusiones del Abogado General señor F. G. Jacobs, presentadas el 8 de julio de 2004, Asunto C-27/02, Petra Engler. 
Sin embargo, como vimos, la gravedad del daño ambiental difiere de la gravedad del daño civil, y la certeza del daño ambiental no camina a la par de la certeza del daño civil. Por estas razones, se proponen dos vías de armonización: a) analizar la gravedad o significancia del hecho dañoso civil ligado a la afectación de un bien, de un interés o de un derecho preexistente, en el que concurra una víctima en calidad de "víctima directa"; b) analizar la certidumbre del hecho dañoso civil según la mayor certeza que revista el daño ecológico.

\section{BIBLIOGRAFÍA}

AleSSANDRI BESSA, Arturo, De la responsabiliad extracontractual en el derecho civil chileno, Santiago, Imprenta universitaria, 1943.

BARros BoUrIE, Enrique, "La responsabilidad civil como derecho privado: notas sugeridas por la reseña de C. Rosenkrantz al Tratado de Responsabilidad Extracontractual”, Estudios Públicos, núm. 112, 2008. BREYER, Stephen G., "Razonamiento económico y revisión judicial”, Estudios Públicos, núm. 109, 2008.

CADIET, Löic, La méthamorphoses du préjudice, en Les méthamorphoses de la responsabilité, Sixièmes Journées René Savatier, París, Presses Universitaires de France, 1997.

CAlABRESI, Guido, El coste de los accidentes: análisis económico y jurídico de la responsabilidad civil, Barcelona, Ariel, 1970.

Cane, Peter, The Anatomy of Tort Law, Oxford, Hart Publishing, 1999.

Cienfuegos Mateo, Manuel, Efectos jurídicos de las sentencias prejudiciales interpretativas del TJCE y su aplicación judicial en los Estados miembros, tesis para obtener el título de doctor en derecho, Barcelona, Universidad Pompeau Fabra, 1995.

Carbonnier, Jean, Droit Civil Les Obligations, 22a. ed., París, Presses Universitaires de France, t. IV, 2000.

Del Pozo PÉREZ, Marta, "Reflexiones sobre la red judicial europea en materia civil y mercantil e Iber-Red”, La Ley, núm. 6717, 21 de mayo de 2007. 
De Miguel Asensio, Pedro, "Competencia judicial en materia de indicaciones geográficas y denominaciones de origen”, en UBERTAZZI y Muniz EsPada (coords.), Le Indicazoni di Qualitá degli alimenti, Diritto Internazionale ed europeo, Milán, Giuffrè Editore, 2009.

, "La protección transfronteriza de los bienes inmateriales en el comercio internacional”, Cursos de derecho internacional y relaciones internacionales deVitoria-Gasteiz 2008, Bilbao, Universidad del País Vasco, 2008.

DieZ-Picazo, Luis, Derecho de Daños, Madrid, Civitas, 1999.

Domínguez ÁGuila, Ramón, "Consideraciones en torno a la noción en la responsabilidad. Una visión comparatista”, Revista de Derecho de la Universidad de Concepción, 1990.

FACH GÓmEZ, Katia, "La prevención de catástrofes, la Unión Europea y el derecho internacional privado", Comunicación presentada en la Jornada Técnica sobre Aspectos Jurídicos, Económicos, y Sociales de las catástrofes, Foro Euromeditarráneo para prevención de Desastres, en http: / / www.proteccioncivil.org/es /DGPCE/Informacion_y_documentacion / catalogo/carpeta04/cd1987-2003/doc/b5/Juridica/3aCom_KatiaFach. pdf [revisado el 25 de abril de 2011].

García Matamoros, Laura y Herrera Lozano, María, "El concepto de los daños punitivos o punitive damages”, Revista Estudios Socio-Jurídicos, Bogotá, Universidad del Rosario, año 5, núm. 1.

GÓmeZ LigüERre, Carlos Ignacio, "Problemas de jurisdicción competente y de derecho aplicable en pleitos de responsabilidad civil extracontractual”, Indret: Revista para el Análisis del Derecho, Barcelona, núm. 2, 2009.

Le Tourneu, Phillippe y CADiet, Löic, Droit de la Responsabilité et des Contrats, París, Dalloz Action, 2002.

MALloy, Robin Paul, Derecho y economía de mercado. Una nueva interpretación de los valores del derecho y la economía, trad. de Carmen Albaladejo, María Cristóbal, Esteban Flamini, Marcial Pons, 2007.

Mazeaud, Henri et al., Leçons de droit civil. Obligation Théorie Générale, 9a. ed., París, Montchrestien, 1998, t. II.

PalaO Moreno, Guillermo, "Hacia la unificación de las normas de conflicto en materia de obligaciones extracontractuales en Europa (una 
visión crítica del Anteproyecto de Propuesta de Reglamento Roma II)", en varios autores, Derecho patrimonial europeo, España, 2003.

POSNER, Richard, "El análisis económico del derecho en el Common Law, en el sistema romano-germánico, y en las naciones en desarrollo”, Revista de Economía y Derecho, vol. 2, núm. 7, 2005.

, El análisis económico del derecho, trad. de Eduardo Suárez, México, Fondo de Cultura Económica, 1998.

RuIz GARCÍA, Juan, “Otra vuelta de tuerca a los daños punitivos”, Revista para el Análisis del Derecho, disponible en http: / /www.indret.com / pdf/438_es.pdf (revisado el 7 de marzo de 2011).

VIneY, Geneviève y Jourdain, Patrice, "Les conditions de la responsabilité”, en Ghestin, Jacques, Traité de Droit Civil, 2a. ed., París, Librairie Générale de droit et de jurisprudence, 1998.

VON BAR, Christian, Gemeineuropä̈sches Deliktsrecht, Múnich, Beck, 1996, t. II.

Sentencias del Tribunal de Justicia de las Comunidades europeas

STJCE $21 / 76$, Rec. p. 1735, asunto Bier vs. Minas de potasio de Alsacia STJCE 33/78 asunto Somafer vs. Saar-Feerngas, STJCE C-26/91 asunto Jakob Handte vs. Mecano Chimoques

STJCE C-364/93, Rec. p. I-2719, asunto Marinari. Apartado 18.

STJCE C-440/97 asunto IE Groupe Concorde y otros vs. Capitaine commandant le navire "Suhadiwarno Pnajan"y otros.

STJCE C-96/00 asunto Gabriel, TJCE C-256/00 asunto Besix. STJCE C-334/00 asunto Fonderie Officine Meccaniche Tacconi STJCE de fecha 18 de mayo de 2006, Asunto C-221/04, Comisión contra Reino de España.

Sentencias del Tribunal Supremo Español

STS 3591/1998. Sentencia del Tribunal Supremo español de 14 de marzo de 2005. Procedimiento: casación.

STS 3625/2007. Sentencia del Tribunal Supremo español. Núm. de Recurso: 2300/2000. Núm. de Resolución: 589/2007. Procedimiento: casación. 
STS 5541/2008. Núm. de Recurso: 942/2003 Madrid dictada el 29 de octubre de 2008.

STS 882/98. Sentencia del Tribunal Supremo español del 28 de enero de 2004. Procedimiento: casación.

Conclusiones del Abogado General del TJCE

Conclusiones del Abogado General Sr. F.G. Jacobs presentadas el 18 de septiembre de 2003, Asunto C-18/02, Danmarks Rederiforening, en nombre de DFDS Torline A/S. Apartados 38-40.

Conclusiones del Abogado General Sr. L.A. Geelhoed, presentadas el 31 de enero de 2002, Asunto C-334/00, Fonderie Officine Meccaniche Tacconi Spa. Apartado 16.

Conclusiones del Abogado General señor F.G. Jacobs, presentadas el 8 de julio de 2004. Asunto C-27/02, Petra Engler.

\section{Directivas, reglamentos y convenios citados}

Directiva 2004/35/CE del 21 de abril de 2004 sobre responsabilidad medioambiental en relación con la prevención y reparación de daños medioambientales.

Directiva 92/43/CEE del Consejo, del 21 de mayo de 1992, relativa a la conservación de los hábitats naturales y de la fauna y flora silvestres.

Directiva 79/409/CEE del Consejo, del 2 de abril de 1979, relativa a la conservación de las aves silvestres.

Reglamento CE 44/2001. Bruselas I.

Reglamento CE 864/2007, Roma II.

Convenio de Berna relativo a la conservación de la vida silvestre y del medio natural de Europa (Decisión 82/72/CEE del Consejo, del 3 de diciembre de 1981).

\section{Documentación}

Comunicación de la Comisión al Parlamento europeo, al Consejo, al Comité Económico y Social europeo y al Comité de las regiones, 
sobre la aplicación de la legislación ambiental comunitaria Bruselas, 18 de noviembre de 2008 COM (2008) 773 final. Disponible en http: / / www.europarl.europa.eu / meetdocs /2004_2009/documents / dv / com_com(2008)0773_/com_com(2008)0773_es.pdf [revisado el 19 de marzo de 2011].

Informe de P. Jenard "Informe sobre el Convenio relativo a la competencia judicial y a la ejecución de resoluciones judiciales en materia civil y mercantil”, D.O.C.E., núm. C189/122 del 18 de julio de 1990. 